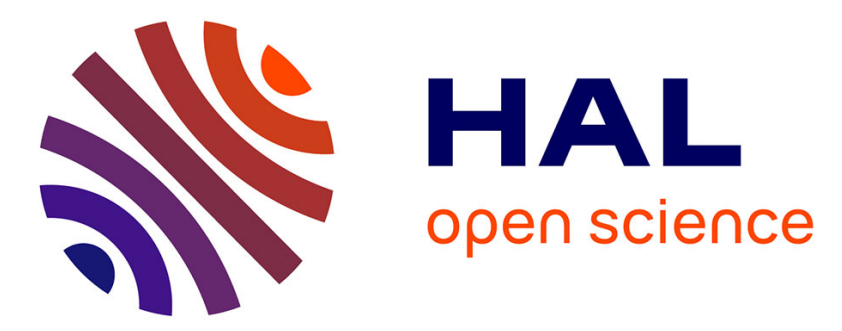

\title{
Benefits and limits of social interaction: The case of mathematical proof
}

\author{
$\mathrm{N}$ Balacheff
}

\section{To cite this version:}

N Balacheff. Benefits and limits of social interaction: The case of mathematical proof. Alan J. Bishop; Stieg Mellin-Olsen; Joop Dormolen van. Mathematical Knowledge: Its Growth Through Teaching, 10, Kluwer Academic Publishers, pp.175-192, 1991, Mathematics education library. hal-01550051

\section{HAL Id: hal-01550051 \\ https://hal.science/hal-01550051}

Submitted on 29 Jun 2017

HAL is a multi-disciplinary open access archive for the deposit and dissemination of scientific research documents, whether they are published or not. The documents may come from teaching and research institutions in France or abroad, or from public or private research centers.
L'archive ouverte pluridisciplinaire HAL, est destinée au dépôt et à la diffusion de documents scientifiques de niveau recherche, publiés ou non, émanant des établissements d'enseignement et de recherche français ou étrangers, des laboratoires publics ou privés. 


\section{BENEFITS AND LIMITS OF SOCIAL INTERACTION:}

\section{THE CASE OF TEACHING MATHEMATICAL PROOF}

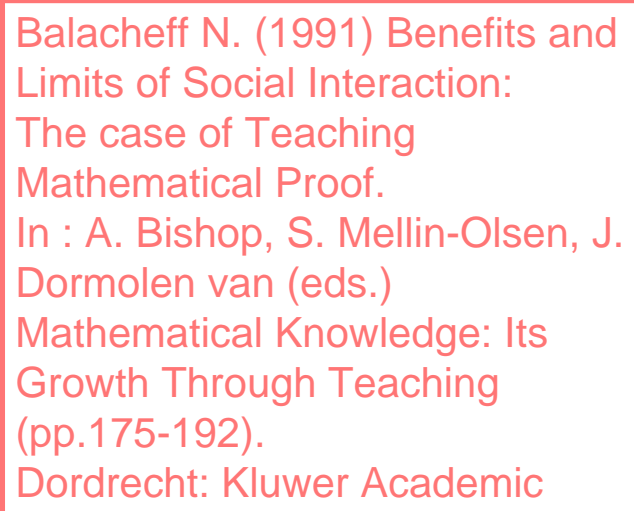

\author{
N. Balacheff \\ IRPEACS-CNRS \\ BP 167 \\ 69131ECULLY CEDEX FRANCE \\ INTRODUCTION
}

Teaching mathematical proof is a target for most of the mathematical curricula. This target is sometimes explicitly stated, I mean that "mathematical proof" can appear as a chapter in the textbook, or it is sometimes pointed out as a general aim of the teaching. In this last case, the aim is the training in the construction and the formulation of deductive reasoning, "mathematical proof" not being named as such. Actually, that is the situation at the present time in France: The last programmes ${ }^{1}$ (1985) for the eighth grade state that students should be trained progressively to construct deductive reasoning, this training must be intensive at the ninth grade. The situation is the same in Québec:

"Développer l'esprit logique de l'élève en l'amenant à structurer ses raisonnement [...] Il convient donc d'exiger que l'élève appuie la solution des problèmes sur un raisonnement logique et structuré"

The situation will be the same in US, following the indication of the recent Standard for School Mathematics: 
"All students, especially the college intending, should learn that deductive reasoning is the method by which the validity of a mathematical assertion is finally established" (NCTM, 1989, p.143).

This objective is very difficult to fulfil as teachers witness it (Gaud \& Guichard, 1984), and as it is established by some research (Bell,1976; Senk, 1985; Usiskin, 1982). There is two reasons very often offered by mathematics teachers as to explain these difficulties, one is the lack of students' awareness of the necessity to give any proof, an other is their lack of logical maturity. But, in my opinion, these explanations are a bit short, insofar as outside the mathematics classroom, there is some evidence that the same students have quite a different behavior. To understand what happens whe have to enter the students world, we have to accept to consider the coherency of their own rational for asserting the truth of a mathematical statement or a result. In other words, we must make our copernician revolution. We will discover that they have some awareness of the necessity to prove and some logic (Balacheff, 1988). But perhaps these are not identical to what we expect them to be, the related open question is "why?". I would like to suggest that the answer to this question, cannot be found just by considering the student isolated. I mean that we have to consider the context in which s/he behaves: Students' behaviors are meaningfull insofar as they are their answer to the situation as they perceive it.

Some research has evidenced that the teaching situation in which students construct the solution to a given problem and in which they formulate it, can lead them to radically transform their initial solution into something they find more suitable to the teacher expectations as they 
understand them. For example, a student I observed ${ }^{2}$ while he was solving a problem with one of his school mate, after having found a solution quite in a good maner, then engaged an odd process just to formulate his solution mathematically. Unfortunatly, the solution he produced then did no longer look like anything coherente. We must realize that in such a situation the teacher has no way to think anything else than that this student behaves at a very low level of logic. This phenomenon is now wellknown to many researchers, and there is a consensus to consider that "students' apparently bizarre [mathematical] behaviors frequently cannot be accounted for solely in terms of conceptual limitations. [There] is a need to move beyond the 'purely cognitive'." (Cobb, 1986, p.2).

Moving beyond 'purely cognitive', what most of the researchers discover is the crucial role played by social issues. As, for example, Lampert stated it:

In the mathematics classroom "doing mathematics means following the rules laid down by the teacher; knowing mathematics means remembering and applying the correct rules when the teacher asks a question; and mathematical truth is determined when the answer is ratified by the teacher." (Lampert,1988, p.437).

These characteristics of school mathematics are of a social nature; and Lampert recognizing it then reports that "changing students' ideas about what it means to know and do mathematics was a matter of immersing them in a social situation that worked according to different rules than those that ordinarily pertain in classroom, and then respectfully challenging 
their assumptions about what knowing mathematics entails." (ibid., p.470). Such a project is at the core of many attempt to modify classroom practices in order to obtain a modification of students' view about what mathematics consist of (e.g. Arsac et Mante, 1983; Capponi, 1986). Shoenfeld (1987) exploring the issue of mathematics as "sense-making" shows that this kind of social considerations are not recent, as for example classroom discussions promoted by Fawcett (1938). What is new now, seems to be the consensus of the mathematics educators' community on the fact that issues related to the social dimension must be considered more carefully. Evidences of the fruitfulness of using social settings to facilitate mathematics learning consist mainly of stories about the success of such attempts. But, as we know such settings do not work with every teacher or in every classroom. Research is needed to strengthen the basement of such approaches. Part of my own research has been to explore the necessary conditions for the success of such settings and thus to explore both benefits and limits of the use of social interactions in the mathematics classroom. It is what I will present now on, focusing on the case of teaching and learning mathematical proof.

THE MEANING OF MATHEMATICAL PROOF:

AN OUTCOME OF SCHOOL PRACTICE.

What a mathematical proof consists of seems clear to all mathematics teachers and mathematics educators. That is: "A carefull sequence of steps with each steps following logically from an assumed or previously proved statement and from previous steps." (NCTM, 1989, p.144). This description is almost the same all over the world, it is very close to what a logician would formulate, perhaps more formally. Comments made on 
mathematical proof as a content to be taught emphasize two points: First they stress that it has nothing to do with empirical or experimental verification, second they call attention on the move from concrete to abstract. Here are examples of such comments:

"It is a completely new way of thinking for high school students. Their previous experience both in and out of school has taught them to accept informal and empirical arguments as sufficient. Students should come to understand that although such arguments are useful, they do not constitute a proof." (NCTM, 1989, p.145).

We can say that the definition of mathematical proof, as an outcome of these official texts is mathematically acceptable, but there is a long way from this definition to the image builted in practice along the teaching interaction. More or less, teaching mathematical proof is understood as teaching how to formulate a deductive reasoning: "Pour les professeurs, une démonstration, c'est très nettement l'exposé formel déductif d'un raisonnement logique" (Braconne, 1987, p.187).

The construction of this reasoning, and its possible relationships with other kind of reasonings, is hidden by that over emphasis on its "clear" formulation. That conception is so strong that some teachers can come to an evaluation of a mathematical proof just considering the surface level of the discourse. For example, in her requirement for teachers comments on a sample of students formulations, Braconne reports ${ }^{3}$ that:

"Les professeurs ont réagi aux longueur inutiles du texte de Bertrand, au désordre dans la solution de

3 The interwievees were 13 French mathematics teachers. 
Karine, au fait que le texte d'Elodie ne suive pas le raisonnement déductif, etc. Toutefois, sept professeurs n'ont pas remarqué que, dans le texte de Bertrand, c'est la réciproque du théorème nécessaire à la démonstration qui était cité au premier paragraphe, et huit n'ont pas signalé que le texte de Laurent contenait la même erreur [...] Donc pour l'élève, et pour nous, les notes ne reflètent pas le fait que le professeur se soit apperçu de l'erreur ou non. " (Braconne, 1987, p.99.).

A report on proof frames of elementary preservice teachers shows a similar behavior:

"Many students who correctly accept a general-proof verification did not reject a false proof verification; they were influenced by the appearance of the argument - the ritualistic aspects of the proof rather than the correctness of the argument. [...] Such students appear to rely on a syntactic-level deductive frame in which a verification of a statement is evaluated according to ritualistic, surface features." (Martin \& Harel, 1989).

Thus, mathematical proof appears ultimately as a kind of rethoric specific to the mathematical classroom, it is not surprising then that it appears as such to the eyes of students. The nature of mathematical proof as a tool to establish a mathematical statement is in some extend hidden by the emphasis onto the linguistic dimension. What does not appear in the school context is that the mathematical proof is a tool for mathematicians for both establishing the validity of some statement, as well as a tool for communication with other mathematicians. 
Beyond a certain complexity, conceptual or technical, how to come to certainty about the validity of the discourse which intends to guaranty the truth of a mathematical result? The precise "symbolic technology" (Bishop, 1988) used to express a mathematical proof is one of the means to shake that validity, but as Manin ${ }^{4}$ recalls, ultimately "a proof becomes a proof after the social act of 'accepting it as a proof'." This social nature of mathematical proofs is part of their practical value, it leads to acknowledge them as reliable and efficient tools for the mathematician. Actually, we should remember that what constitute the present consensus about rigor has not been created ex nihilo, it is the product of an historical and a social process within the community of mathematicians 5 .

There is an other reason for considering so strongly the social dimension of mathematics teaching and learning. For as we recognized that learning is a personal process, we should also consider that its outcome is likely to be firstly a private knowledge: The students' conceptions. But that conflicts with two constraints specific to the teaching, which has to guarantee the socialization of students' conceptions for the following reasons:

- Mathematics is a social knowledge. Students should make their own the knowledge that exists outside the classroom. It has a social status in society, or in smaller social groups under whose control it is used. For example, the community of mathematicians or that of engineers can be taken as a social reference.

4 Manin quoted by Hanna (1983).

5 The essay of I. Lakatos (1976) on the dialectic of proofs and refutations gives a good insight of this historical process. 
- The mathematics class exists as a community. The teacher has to obtain a certain homogeneity in the meaning of the knowledge constructed by students, and she or he has to ensure its coherence. Otherwise, the functioning of the class will hardly be possible. Because of the constructivist hypothesis we consider, the use of authority is not desirable. Thus the homogenization can only be the result of a negotiation or of other specific social interactions such as the one Brousseau (1986) has described in the frame of his théorie des situations didactiques.

\section{SOCIAL INTERACTION AND SITUATIONS FOR VALIDATION}

What is now clear is that as long as students rely on the teacher to decide of the validity of a mathematical outcome of their activity, the word 'proof' will not make sense for them as we expect it to do. In such a context they are likely to behave mainly to please their teacher, just as one of the British students interviewed by Galbraith (1979) told his interviewer: "To prove something in maths means that you have worked it out and it proves how good you are at working questions out and understanding them."

But it is not sufficient to propose a problem to the mathematics classroom, and to tell the students that they have the responsability of solving it. There is no reason for them, a priori, to consider that that problem is their problem and to feel committed in solving it; they can still think that they have to do so in order to please the teacher and thus there behavior will not be much significant.

Before going ahead, let us consider a short story told by Sir Karl Popper, it will throw a relevant light on what we want to suggest:

"If somebody asked me, 'are you sure that the piece in your hand is a tenpenny piece?' I should perhaps glance 
at it again and say 'yes'. But should a lot depend on the truth of my judgement, I think I should take the trouble to go into the next bank and ask the teller to look closely at the piece; and if the life of a man depended on it, I should even try to get to the Chief Cashier of the Bank of England and ask him to certify the genuineness of the piece." (Popper, 1979, p.78).

And then Popper adds that "the 'certainty of a belief is not so much a matter of its intensity, but of the situation: Of our expectation of its possible consequences." (ibid.)

On the same line, I would like to suggest that if students do not engage in any proving processes, it is not so much because they are not able to do so, but rather that they do not see any reason. Even if they engage such a process, its level depends heavily on the way students understand the situation. Following a principle of economy of logic they are likely to bring into play no more logic than what is necessary for practical needs" (Bourdieu, 1980, p.145).

Then the true meaning of the outcomes of students proving processes, and even the fact that they enter or not such a process, is to be traced in the characteristics of the situation in which they are involved.

In situations in which they have to decide of a common ${ }^{6}$ solution to a given problem students have to construct a common language and to agree on a common system to decide of the validity of the solution they propose. The essential role of the social dimension, mainly in situations for communication, provoking a move from "doing" to "telling how to do", and

6 By 'common', we mean here a solution supported by the whole classroom, or smaller groups of students as it is usually the case. 
their importance in the construction of meaning have been put in evidence by Brousseau in his théorie des situations didactiques (Brousseau, 1986). Here we would like to recall what this author wrote about the situations for validation:

The situations for validation "will bring together two players who confront each other regarding a subject of study composed on the one side of messages and descriptions produced by the pupils and on the other side of the a-didactic milieu milieu used as referent for these messages. The two players are alternately a 'proposer' and an 'opposer'; they exchange assertions, proofs and demonstrations concerning this pair 'milieu/message'. This pair is a new apparatus, the 'milieu' of the situation for validation. It can appear as a problem accompanied by the attempt at solving it, like a situation and its model, or like a reality and its description...

While informer and informed have disymetric relations with the game (one knows something that the other does not know), the proposer and the opposer must be in symetrical positions, both regards the information and means of action about the game and the messages which are at their disposal, and as regards their reciprocal relations, the means of sanctionning each other and the objectives vis-à-vis the pair milieu/message." (Brousseau, 1986, p.158).

We should realize that in such situations, behaviors that are more social than mathematical, would probably apprear. For example, because of 
self-esteem, some students might refuse to recognize that they are wrong, or others might refuse to accept that their opponants are right.

Thus, to summ up, to provoke students proving behaviors we should design situations in such a way that students come to realize that there is a risk attached to uncertainty, and thus that there is are an instest to find a good solution. In order to obtain a significant scientific debate among students, we should provide them with a situation promoting contradiction, but also promoting acceptance. Otherwise systematic rejection could become an efficient defensive strategy. In other words the situation should allow the recognition of a risk linked to the rejection of a true assertion, or to the acceptance of a false one.

Following these principles we have designed teaching situations as experimental settings in order to study students behaviors in such contexts, and the nature of these behaviors in relation to the characteristics of these situations. A priori, we thought that genuine mathematical proving processes will be observed, a deep analysis of our experiments shown that things are a bit more complex than what is usually aknowledge by innovative practice resting on social interaction.

In the following section we will report, in some details, on one of these experiments.

EVIDENCES FROM A CASE STUDY 7

7 The scase study reported here has been made possible because of the close relationships established between academics and teachers within a research group of the IREM de Lyon. It is a small part of a four years project which had allowed us to collect a large amount of data. The complete report is available from the IREM de Lyon, Université Claude Bernard, Lyon. 
A first principle we wanted to satisfy in designing the experiment was to obtain the devolution 8 of the responsability for the validity of the problem's solution from the teacher to the students. For that purpose we have chosen a context of communication: We told the students that they will have to write a message for other students, of the same grade, in order to allow them to solve a given problem. In such a situation the criteria for success are left to be decided by students according to their own means for the evaluation of the efficiency and the reliablity of the message they have produced. We thought that this setting would be sufficient to ensure that students will consider that they have the responsability for the truth of their solution, and that they will not refer to the teacher expectation

In such a situation there is usually some tensions because of the different individual motivation and commitment. For this reason, we think that it is not desirable to ask the students to work individually, but on the other hand it is not desirable to ask for a collective production form the whole class insofar as some students might feel that they are not conerned, leaving the job to the others. So, we decided to constitute small teams of three to four students working together, telling them that the final solution will be one of the ones proposed by the teams, or a modification of it. To promote a collective work, each team must propose only one solution, and during the debate for the choice of the class solution the team will be asked to express its position trough the voice of a chosen representative. That constraint obliges students to explicit and to discuss a priori the goodness and fitness of what they want to be said. We think that the quality of the 
debate will rest on the motivation of each team, its willingness to have its message chosen, but also its commitment in the success of the class as a whole.

The mathematical problem we chosen was the following :

Write for other students, a message allowing them to come to know the perimeter of any triangle a piece of which is missing. To do it, your colleagues will have at disposal only the paper on which is drawn a triangle and the same instruments as you (rules, etc.).

Together with this text a triangle as the following (fig.1) were given to the students. All the teams in the classroom had the same materials.

Figure 1 about here

The study we made before this experiment (Balacheff, 1988, pp.321360), allowed us to think that all the students will be able to enter the problem-solving process, with quite different solutions. This diversity was expected to be the source of interesting debates. We know that some students, and thus some teams, will miss the fact that the solution must work for a general case and not only for the triangle given as an example. But we were sure that this will be pointed out during the debate, and then that it will be taken in consideration, even with more strenghth than if the teacher had warned about it a priori.

The role of the teacher was to present the situation, then not to intervene in any case up to the time when all the teams have proposed a solution; then its position will be to regulate the debate and to give the floor to the teams' representatives. The end of the sequence will come from a general agreement on the fact that one of the solution, or a new one obtained as a result of the interactions, is accepted. The debate was 
organised in the following way: The messages were written on a large sheet of paper and then they were displaid on a wall of the classroom. Each team had to analyze the messages and their representatives had to tell the class their critics and suggestions. These critics had to be accepted by the team which were the author of the message discussed. In case of an agreement of the class on a false solution, the teacher were allowed to propose to the teams a new triangle invoking that such a triangle might be considered by the receptors (such material had been prepared taking into account what we knew from the first study). On the other hand if more than one message are acceptable with no clear decision from the class then the teacher was supposed to organise a vote to make the choice, asking the students to tell the reasons for their choice.

I will not here report in details on the analysis of this experiment, a complete report is available in Balacheff (1988, pp.465-562). I will here focus only on the outcomes relevant to my present purpose, they are related to the observations which has been made in two different classrooms.

\section{The first experiment}

The first experiment has been carried out with students of the eighth grade (13 to 14 years old). The teacher were a member of the research team, that means that we were in a good position to assert that the project was wellknown to her. The observations have lasted two sessions of 1:30 hours. After the first one we felt really happy with what had happened, after the second phase araised the feeling of some difficulties ... beyond these feelings only the close analysis of the data gathered, led us to discover the existence of the parameters which have played a critical role in the teacher decisions, and thus in the students behaviors: 
- First, a constraint of time, which make the teacher intervening in order to ensure that the whole process will keep within the limits imposed by the general shool time-table in which the experiment took place.

- Second, the teacher willingness to guaranty an acceptable end in her own eyes. There were a huge tension between this willingness and the willingness of not braking the contract of "non intervention". This tension is the indication of what we would like to call in the future : the teacher epistemological responsability.

Because of these two constraints the decisions the teacher made, tend to oppose the devolution of the problem. In particular, to guaranty that the problem solving phase will not be too long, the teacher invited students to propose a solution as soon as she thought that it was mature enoughth, but with no informations about the real feeling of these students. Also, some teacher's interventions aimed at call the attention of students to the word "any" (in the sentence "any triangle"), doing so she did not think that it was a mathematical intervention, insofar as she thought that it was only due to the students' lack of carefulness. But all these intervention led students to a feeling of dependance and the idea on a possible responsability of the teacher for the validity of their answer.

A significant phenomenon, is that the teacher (as well as the observers) did not realize what a continuous contact she kept with the students, making about one intervention every minutes over a 80 minutes periode. The content of these intervention could have been light, as: "Are you O.K.?", or more important as: "Are you sure you have carefully read the statement of the task? ". All together we have counted, within these interventions, 129 different items. We see this phenomenon as an indicator of the intensity of the relationships between the teacher and the students in a situation that we thought to be quasi-isolated from the teacher before we did a close analysis of the records. 
The same constraints were an obstacle to the functionning of the second phase. After a first exchange of critiques by the teams' representatives, the teacher intervened because she thought that nothing positive will come out of the engaged process - at least within the time available. The teacher then try to facilitate the progress in the discovery of a solution, calling explicitely for ideas and suggesting to start from them to go further. Actually it was quite clear from her attitudes that not all the ideas were of the same value:

"Il y en a qui m'ont dit que les médiatrices ça semble intéressant, donc essayer de retravailler sur les médiatrices... en utilisant donc les médiatrices essayez de résoudre le problème qui vous est posé... on va refaire un message, si vous voulez refaire le même travail que vous avez fait hier... mais en partant pas tout à fait comme hier, car vous avez déjà des idées qui sont sorties. Alors on va essayer de répartir le travail, je ne sais pas là moi... il y a trois idées..." (NB, p.518).

The students' behaviors were deeply transformed by these interventions, they got confuse and they no longer be committed in any real discovery of a solution.

The teacher thought that she had kept the spirit of the sequence, the basic frame being: search for a solution, critics, new ideas and suggestions to go ahead. But only the superficial aspects of the intended sequence were still there, its meaning for the students were fundamentally changed. They did not enter a true mathematical activity, as expected, but just a new school game not so different, beyond the new and exiting social setting, from the ordinary one. As the teacher aknowledged "off the record": "Là, ils ne cherchent plus, ils sont prêts à accepter n'importe quel message ... 
alors qu'ils avaient des arguments contre ... ils ne les ressortent pas." (NB, p.527).

\section{The second experiment}

We learned a lot from this first experiment, and we thought that it would be worthwhile to make a second one. We decided to keep the same general framework, but to overcome the obstacles we came to be faced with, we chosen the three following modifications:

(i) To observe a tenth grade classroom in order to be sure that no mathematical difficulty will disturb the phenomenon we wanted to observe. Also, at this level students have already been introduced to mathematical proof. The situation could be an opportunity to enlight its power as a means for proving ...

(ii) To open the time, that means that we decided to leave open when the end of the experiment will end up. We thought that three or four sequences of about one hours will be sufficient.

(iii) To ask the teacher not to intervene, as stricktly as possible, during the first phase (the initial problem-solving phase), and then to act just as a chairperson and as the collective memory ${ }^{9}$ of the class during the second phase (the debate).

The first phase ${ }^{10}$ did not present any special particularity. The teacher did not intervene at all, leaving students free to decide that they have a

9 To be the "memory" of the class means to take a record of what is said, in particular by writing students' decisions on the blackboard.

10 This phase took about one an hour. 
solution to propose. Four teams among the five reached a solution, the fifth one which were clearly close to surrender, finally proposed a "contribution" to the collective effort, as a response to the teacher demand.

During the second phase also she followed the specifications we decided together. Then ...

More than a scientific debates, that is, proposing proofs or counterexamples, the data show that students entered a discussion with some mathematical content in it, but which mainly consisted of an exchange of arguments pro et contra not necessarily connected the ones to the others. They argue about the different proposed solutions, but they do not prove mathematically.

The situation for communication has really been taken into account as such by students, as their remarks on the proposed messages show it. The main critics are related to the fact that this message must be understandable and usable by its receptors:

"Il faut qu'il soit compréhensible pour tout le monde" (C920).

"Faut se mettre à la place de quelqu'un qui sait pas ..." (E559).

But the problem of the validity of the proposed solution is not really considered. In that sense we can say that the situation does not realize a situation for validation. For a clear distinction between "argueing" and "proving" in mathematics 11 , we refer to the distinction as formulated by Moeschler:

"Un discours argumentatif n'est pas un discours apportant à proprement parler des preuves, ni un

\footnotetext{
11 We do not refer necessarily to formal proof, or mathematical proof in the classical sense.
} 
discours fonctionnant sur les principes de la déduction logique. En d'autres termes, argumenter ne revient pas à démontrer la vérité d'une assertion, ni à indiquer le caractère logiquement valide d'un raisonnement [...] Un discours argumentatif, et c'est là une hypothèse de départ importante, se place toujours par rapport à un contre-discours effectif ou virtuel. L'argumentation est à ce titre indissociable de la polémique." Moeschler (1985, p.46-47)

In that sense, what we have observed is first of all an exchange of arguments about the simplicity of the solution :

"Je trouve que c'est trop simple... je veux dire, ils démontrent pas comment trouver le périmètre d'un triangle, ils disent juste... ils tracent des droites. Tout le monde peut le faire." (B224).

... or of its complexity:

"Alors, nous on est tous d'accord sur le fait ... qu'on refuse le message ... Alors refusé : premièrement il est trop compliqué ... trop compliqué, pas assez clair." (E 434).

The context of a communication with other students has favoured the feeling of the relevance of critics in that register. But what leads us to suggest that this debate is more an argumentation than a scientific debate, in the Moeschler sense, is the fequent lack of logical relationships between arguments. Even more, some students can pass in the same argumentation from one position to an other completly contradictory:

"On est tous d'accord pour refuser ... alors parce que d'abord le message est trop compliqué et puis c'est plus un message, c'est le problème en entier. Ils font le 
problème ... ils calculent, ils font déjà tous les calculs" (D458)

"c'est facile quand même, puisqu'ils nous mettent déjà tout" (D592).

These arguments can have nothing to do with mathematics, or even with what is required by the situation:

"Pour un problème comme ça c'est trop simple ... quant on voit ce message, pis quand on voit celui-ci [messageB] on pourra deviner que les maths c'est des machins compliqués." (C230)

... and it could be the same for the objections opposed to an argument, like in the following example:

This argument is opposed to the argument of the team

$\mathrm{B}$ against the too easy message A (cf. above, B224): "S'il dit que c'est trop facile c'est qu'il a réussi à le faire, donc il n'a pas à marquer qu'il a refusé" (E275).

Finally, the involvement of some of the teams in the game, I mean the fact that they are eager to winn, had favoured the appearance of polemics: The strongest opponants to the "too complex" message are the authors of the "too simple", and inversely.

After a first period of debate the messages have been accepted, provided that some modifications are to be made, but their validity have not been really discussed. So, the teacher proposed a new triangle, in order to challenged the messages. This triangle was such that the wrong solutions will obviously fail. The debate following this checking phase, shows how strongly students are more involved in an argumentation than in a scientific debate:

"Tout à l'heure il était réalisable." (D1465) 
"Nous on l'a refait le message avec l'autre feuille, c'est pas notre faute s'ils nous en donnent une plus petite." (D1492)

"Oui, mais c'est un triangle quelconque ... Y faut que ça marche dans tous les cas. Ici ça marche pas." (E1493)

"Ça prouve que ça marche pas avec n'importe quel triangle, c'est tout" (D1501)

"Tout à l'heure il a bien marché là, pourquoi il n' a pas marché ici ... ce serait un coup du hasard." (D1550)

Finally, one solution being accepted as the solution of the class, the teacher asked students whether they were sure of that solution. They answer: "Yes because we have done it in a lot of cases." So, it is even not sufficient to directly address the question of the validity. Note that when latter on the teacher asked the students about a possible mathematical proof of their solution, they gave one showing that technically it was in their possibility.

\section{DISCUSSION}

\section{Efficiency versus rigor}

Even if we are able to set up a situation which characteristics promote content specific students interaction, we cannot take for granted that they will engage a "mathematical debate", and finally that they will produce a mathematical proof.

A particularity of mathematics is the kind of knowledge it aims at producing. Its main concern is with concepts specific to its internal 
development. There is evidence that Egyptians used intellectual tools in practical situations for which we have now mathematical descriptions, but the birth of mathematical proof is essentially the result of the willingness of some philosophers to reject mere observation and pragmatism, to breack off percepion (the monde sensible), to base knowledge and truth on Reason. That actually is an evolution, or a revolution, of mathematics as a tool towars mathematics as an object by irself, and as a consequence a change of focus from "efficiency" towards "rigor".

It is a rupture of the same kind which happens between "practical geometry" (where students draw and observe) and "deductive geometry" (where students have to establish theorems deductively). Also in mumerical activities, like the one reported by Lampert (1988), the same rupture happens when students have no longer to find some pattern out of the observation of numbers, but that they have to establish numerical properties in their "full" generality (using letters and elementary algebra).

We have here to realize that most of the time students do not act as a teoretician but as a practical man. Their job is to give a solution to the problem the teacher has given to them, a solution that will be acceptable with respect to the classroom situation. In such a context the most important thing is to be effective. The problem of the practical man is to be efficient not to be rigorous. It is to produce a solution not to produce knowledge. Thus the problem solver does not feel the need to call for more logic than is necessary for practice.

That means that beyond the social characteristics of the teaching situation, we must analyse the nture of the target it aims at. If students see the target as "doing", more than "knowing", then their debate will focus more on efficiency and reliability, than on rigor and certainty. Thus again argumentative behaviors could be viewed as being more "economic" than 
proving mathematically, while providing students with a feeling good enought about the fact that they have completed the task.

\section{$\underline{\text { Social interaction revisited }}$}

Social interaction, while solving a problem, can favour the appearance of students' proving processes. Insofar as students are committed in finding a common solution to a given problem, they have to come to an agreement on the acceptable ways to justify and to explain their choices. But what we have shown is that proving processes are not the only processes likely to appear in such social situations, and that in some circumstances they could even be almost completly replaced by other types of interactional behaviors. Our point is that in some cicumstances social interaction might become an obstacle, when students are eager to succeed, or when they are not able to coordinate their different points of view, or when they are not able to overcome their conflict on a scientific basis ${ }^{12}$. In particular these situations can favour naive empiricism, or they can justify the use of crucial experiment in irderto obtain an agreement instead of proofs at an higher level (Balacheff, 1988).

Perhaps some people might suggest that a better didactical enginery could allow us to overcome these difficulties; indeed much progress can be made in this direction and more research is needed. But we would like to suggest that "argumentative behaviors" (i) are always potentially present in human interaction, (ii) that they are genuine epistemological obstacles ${ }^{13}$ to

\footnotetext{
12 I mean, content specific

13 The notion of "epistemological obstacle" has been coined by Bachelard (1938), and then pushed on the forefront of the didactical scene by Brousseau (1983). It refers to a genuine piece of knowledge which
} 
the learning of mathematical proof. By "argumentative behaviors" we mean behaviors by which somebody tries to obtain from somebody else the agreement on the validity of a given assertion, by means of various arguments or representations (Oléron, 1984). In that sense, argumentation is likely to appear in any social interaction aiming at establishing the truth or falsehood of something. But we do consider that argumentation and mathematical proof are not of the same nature: The aim of argumentation is to obtain the agreement of the partner in the interaction, but not in the first place to establish the truth of some statement. As a social behavior it is an open process, in other words it allows the use of any kind of means; whereas, for mathematical proofs, we have to fit the requirement for the use of a knowledge taken in a common body of knowledge on which people (mathematicians) agree. As outcomes of argumentation, problems' solutions are proposed but nothing is never definitive (Perelman, 1970, p.41).

Insofar as students are concerned, we have observed that argumentative behaviors play a major role, pushing on the backside other behaviors like the one we were aiming at. Clearly enought, that could be explained by the fact that such behaviors pertain to the genesis of the child development in logic: Very early, children experience the efficiency of argumentation in social interactions with other children, or with adults (in particular with its parents). Then, it is quite natural that these behaviors appear first when what is in debate is the validity of some production, even a mathematical one. 
So, what might be questionned is perhaps not so much the students' rationality as a whole, but the relationships between the rational of their behaviors and the characteristics of the situation in which they are involved. Not surprinsingly, students refer first to the kind of interaction they are already familiar with. Argumentation has its own domain of validity and of operationality, as all of us know.

So, in order to teach successfully mathematical proof, the major problem appears to be that of negociate the acceptance by the students of new rules, but not necessarily to obtain that they reject argumentation insofar as it is perhaps well adapted to other contexts. Mathematical proof should be learned "against" argumentation, bringing students to the awareness of the specificity of mathematical proof and of its efficiency to solve the kind of problem we have to solve in mathematics.

Negociation is here the key process, for the following reasons:

- First, because the teaching situation cannot be delivered "open" to the students otherwise many of them will not understand the point and they will get lost. The following quotation from Cooney makes it clear:

"Maybe not all of them but at least some of them felt 'I am not going to participate in this class because you [referring to the teacher] are just wasting my time. It is so ironic because if I was doing the type of thing they wanted to do, they would be turning around in their seats and talking. So it's a no-win situation." (Cooney,1985, p.332).

- Second, because the rules to be followed, the true aim of the teacher cannot be stated explicitly. If the rules for the interaction are explicitly stated, then some students will try to escape them or to discuss them just as many people do with law. Also because interacting mathematically might then become "mastering a few clever techniques" which may turn into 
objects to be taught, just as teaching "problem solving" has often become teaching quasi-algorithmic procedures (Schoenfeld, 1985).

The solution is somewhere else, in the study and the better understanding of the phenomena related to the didactical contract, the condition of its negociation, which is almost essentially implicit, and the nature of its outcomes: the devolution of the learning responsability to the students. We cannot expect ready to wear teaching situations, but it is reasonnable to think that the develoment of research will make available some knowledge which will enable teachers to face the difficult didactical problem of the management of the life of this original society: The mathematics classroom. 


\section{NOTES}

